League Bilong Laif: Rugby, education and sport-for-development partnerships in Papua New Guinea

Emma Sherry

La Trobe University

Centre for Sport and Social Impact

Bundoora, Australia

e.sherry@latrobe.edu.au

Nico Schulenkorf

UTS

Business School

Sydney, Australia

Full citation:

Sherry, E., \& Schulenkorf, N. (2016). League Bilong Laif: rugby, education and sport-for-development partnerships in Papua New Guinea. Sport, Education and Society, 21(4), 513-530. doi:

$10.1080 / 13573322.2015 .1112780$ 
League Bilong Laif (LBL) is a sport-for-development program that was established in 2013 as a threeway partnership between the Australian Government, the Papua New Guinea (PNG) Government (Department of Education), and the Australian Rugby League Commission (National Rugby League [NRL]). As a contribution to addressing low rates of school attendance and significant problems with anti-social behaviour within PNG communities, LBL was designed to contribute to 1) improvements in student engagement with education in and out of the classroom; and 2) communication of positive social messages, with a focus on respect generally, and gender equity in particular. This paper discusses the qualitative review of the pilot phase of the LBL project, and the implications for program design and delivery for education outcomes through a sport-for-development program. Data was collected through a combination of 23 interviews and focus groups with 33 individual representatives from relevant organisations and government departments in the areas of sport, education and community development. Preliminary findings indicate that despite a challenging beginning, the LBL program has made some progress in terms of the initial development of program aims and stakeholder engagement, largely because of the rigorous design process that kept desired program outcomes at the forefront.

Key words: sport for development, education, developing nation, rugby league, qualitative research, program evaluation. 


\section{League Bilong Laif: Rugby, education and sport-for-development partnerships in Papua New Guinea}

\section{Introduction}

Papua New Guinea (PNG) provides a unique and challenging context for the implementation and analysis of sport and development projects; the Pacific nation is culturally and linguistically diverse and has a difficult history of inter-group tension and geographic isolation. PNG also suffers from low rates of school attendance and has significant problems with anti-social behaviour and gender inequity. The mean years of schooling in PNG amount to just 3.91 years, adult literacy is $62.4 \%$ and only $10.5 \%$ of the current adult population (aged 25 years and older) have attended secondary school (UNDP, 2015). PNG ranks at $124 / 136$ on the UNDP's gender development index, placing it in the bottom $10 \%$ of countries worldwide.

In an attempt to address some of the socio-educational issues listed above, the League Bilong Laif (LBL) program began in 2013 as a three-way partnership between the Australian Government, the PNG Government, and the Australian Rugby League Commission. LBL was strategically designed to contribute to the following development outcomes:

1. Improved quality of education for girls and boys of all abilities in PNG through rugby league and related activities.

2. Increased capacity of teachers - through resources and training - to conduct rugby league-based development activities in the school environment.

3. Improved organisational and management capacity of the PNG rugby league federation (PNGRFL) to manage the development and delivery of school-based rugby league in PNG.

From its official launch, the LBL organisers and stakeholders were very clear in articulating that the program was an education initiative, not simply a sports program. The organisers share this approach of using sport as the vehicle for wider community development outcomes with the growing number of sport-for-development (SFD) initiatives around the world; however, in comparison to projects aimed at achieving social change (Bailey, 2005; Sherry, 2010), improvement in health (Casey, Payne \& Eime, 2009; Eime, Young, Harvey, Charity, 
\& Payne, 2013), reduction of anti-social behaviour (Ekholm, 2013) or reconciliation and peace outcomes (Sugden, 2006; Schulenkorf, 2010a), the area of education has so far been neglected. While numerous studies have previously focused on developments in physical education and sporting performance, research on educational capacity building and studies on the management of the SFD-education nexus have so far been limited (for notable exceptions, see Armour \& Duncombe, 2012; Burnett, 2014; Jeanes, 2013). Addressing this gap, our paper draws on the qualitative evaluation of the pilot phase of the LBL project and explores the nuances and complexities of SFD program delivery. More specifically, we provide a snapshot of the current state of play with LBL in PNG in relation to the educational components of the program. The pedagogical approaches utilised to train program staff and teachers, the difficulties and strengths of adopting such methods and wider practical recommendations for SFD programs will be outlined in the sections to follow.

\section{Literature context}

Practical projects and research studies in the field of SFD have grown substantially over the past decade. In the broadest sense, the purpose of SFD has been described by Richards et al. (2013) as "the intentional use of sport, physical activity and play to attain specific development objectives in low- and middle income countries and disadvantaged communities in high income settings" (p. 1). Sport has been advocated as a tool to foster community agency, promote social inclusion amongst minority groups, provide HIV/AIDS education and develop the social capital of participants (Beutler, 2008; Burnett, 2006; Jeanes, 2013). However, there is substantial critique aimed at the 'lofty goals' of SFD work with the pervading argument that sport is not a panacea for societal issues (Coalter, 2010; Spaaij, 2009).

As noted by Manley, Morgan and Atkinson (2014), recent literature related to SFD work has, for example, deployed structural analyses and critical investigations to expose the dominant power relations operating in SFD program practices and delivery (e.g. Black, 2010; Darnell, 2010; Darnell \& Hayhurst, 2011, 2012; Hayhurst 2009). However, there has been limited academic analysis of the views and perceptions of those involved in the delivery of SFD programs, particularly in regards to local program staff and stakeholders. This paper seeks to account for such omissions by exploring the values and beliefs of those involved with orchestrating and implementing the LBL program. By examining their views and underlying development processes, this analysis intends to further our understanding of 
education-orientated SFD programs through exposing the nuances and complexities that pervade interactions between program partners including local staff, local schools, communities and teachers.

In this context, partnerships in SFD have been argued to be critical to positive program outcomes (Casey, et al., 2009), sustainability (Hawe, Noort, King, \& Jordens, 1997), and capacity building (Edwards, 2015). Therefore, it is imperative that research addresses the dynamics of such partnerships at the 'micro' level to comprehend how interactions shape program implementation. Unpacking such interactions and embedding these within the wider cultural and social context of PNG provides an important insight into the complexities associated with attempting to elicit education (development) outcomes in a complex sociocultural environment. Edwards (2015) argued that there is "evidence that many SFD practices can effectively facilitate dimensions of community capacity when conducted in intentional, culturally relevant ways" (p. 15); Svenson and Hambrick (in press) likewise argued that leveraging local partnerships can increase organisational capacity and opportunities for programmatic success and sustainability if implemented meaningfully. The role of local partnerships in assuring cultural relevance is thus argued to be critical.

Key partners of SFD programs that significantly influence SFD processes and outcomes are coaches, program facilitators or change agents (Bodey et al., 2009; Schulenkorf \& Sugden, 2011). For example, Bodey et al.'s (2009) conceptual paper discussed the important role of the coach in the development of life skills. The authors argued that for successful outcomes, SFD sessions must be developed around a strong understanding of participants' current skills, ages and desired outcomes; life skill lessons, embedded within the sporting activity, are supposed to be implemented in three phases: message, reinforce, and transfer (Bodey, et al., 2009). Here, the roles of the coach and supporting delivery staff are argued to be critical to successful learning of life skills (Bodey, et al., 2009). Earlier, Hastie and Buchanan (2000) had empirically examined life skill development in school-aged boys as a result of their participation in a program designed around teaching of personal and social responsibility (TPSR) principles. The authors argued that the constructivist learning style of their program - which includes student empowerment, problem solving and the coconstruction of a social "environment in which the individual, while attempting to develop personal responsibility, is placed in a situation in which those decisions have an impact on others" (Hastie \& Buchanan, 2000, p. 33) - are central to making a relevant and meaningful difference. These arguments are conceptually similar to Edwards' (2015) "learning culture" 
environment which foregrounds capacity-building and local ownership as an outcome of meaningful partnerships in SFD.

As previously outlined, there is relatively limited literature discussing educational outcomes and capacity building as part of SFD program aims. In one of the few studies that focused specifically on school attendance and social engagement as educational outcomes, Armour and Duncombe (2012) examined the impact of using role models and mentors in a school-based sport program on improved school attendance and overall classroom behaviour. The authors noted an "immediate positive reaction to the activities" with positive engagement of students with sport role models. However, the study also acknowledged that "there was limited evidence of a wider impact on young people's behaviour, school attendance or selfesteem" (p. 381), confirming Coalter's (2008) assertion of the critical importance of appropriate strategic, holistic and long-term planning for desired SFD outcomes.

In one of the few studies to examine SFD in an education context in a lower middle income country (LMIC), an increase in students' pro-social behaviour was noted by Burnett (2014) in her examination of an SFD program in South Africa. Teachers, too, reported personal and professional benefits, such as improved fitness, feeling better about themselves and gaining students' trust. In a more critical investigation of an SFD initiative in Zambia, Jeanes (2013) situated participants' views at the centre of her analysis of peer-led programs aimed at HIV/AIDS education. The study revealed that although young people benefited from the overall program content, their capacity to affect wider social change and to disseminate their new knowledge beyond the sporting ground was severely constrained by their lack of power within their communities. The study thus provides a real world example supporting Coalter's (2010) concerns about SFD programming's often narrow focus in the context of broad gauge problems. In recommending improvements for future program design and delivery, Jeanes (2013) argued that SFD programming "requires a multi-agency approach involving young people and sports NGOs collaborating with health and other agencies and dominant groups within local communities" to challenge and reshape "norms and values at every level" (p. 403).

The need for locally grounded understanding and engagement was further raised in Spaaj and Jeanes' (2013) research into pedagogies employed within the context of SFD initiatives. The authors argued that the use of traditional didactic, peer education and relationship-building pedagogies currently "do not go far enough in providing a truly 
transformative educational experience for participants" (Spaaij \& Jeanes, 2013, p. 442). It was contested that externally imposed pedagogies may negatively impact program outcomes as they tend to undervalue existing knowledge. In the authors' words, there is a strong risk of imposing neoliberal philosophies that tend to view marginalisation and vulnerability as the inevitable result of individual failure rather than as situated within "the sociohistorical workings of power in society" (Spaaij \& Jeanes, 2013, p. 448).

Overall, despite the relatively small amount of research examining SFD programs in LMICs, there is a common understanding of the need for a situated, strategic and informed design of program interventions that accounts for all contextual factors, including resources, local partners and socio-political context. The present paper builds on these foundations and aims to develop previous work that has focused on educational outcomes/capacity building. In particular, we provide a greater insight into the challenges and benefits associated with delivering SFD in a complex socio-cultural environment and with training local school teachers to deliver a particular program respecting and utilising the underlying program philosophy, approach and methods.

\section{Social Context}

Given the complexity of the social and cultural context surrounding LBL in PNG, it is important to provide a brief overview of the critical factors most pertinent to the design and delivery of the SFD program. PNG lies within the southern tropics, around 160 kilometres north of Australia; the country comprises the eastern half of the island of New Guinea and approximately 600 offshore islands. The PNG mainland and larger islands are exceptionally mountainous, rugged, largely inaccessible by vehicles, and subject to active volcanism, earthquakes, mudslides and tsunamis. Since 2013, the current PNG Government has been implementing its election promise of free schooling for all PNG children across the country. Elementary, primary and secondary schooling is now freely available; however, a number of challenges restrict regular attendance. First, the geographic spread of schools and their inaccessibility in remote areas impact children's ability to attend classes. Second, challenging weather conditions and, in urban regions, traffic congestion present logistical challenges for school children and extra-curricular sport providers such as LBL. Third, PNG is linguistically and culturally diverse; its four million strong population speaks some 800 distinct languages and dialects, and more than 200 discrete cultures have been identified. 
Moreover, numerous regions in PNG are known for inter-cultural conflict, intercommunity tensions and tribal fights, particularly in the PNG highlands and in the autonomous region of Bougainville. During times of open conflict, schools remain closed or are too dangerous to access, including in the country's capital Port Moresby. Highlighting the severity of safety concerns, the Economist Intelligence Unit's liveability index ranks Port Moresby 137/140 countries, stating that "most aspects of living are severely restricted". On a general level, criminality rates are some of the highest in the world, significantly impacting the ability to stage sport projects in certain areas and communities (OSAC, 2015).

In regard to educational development, a number of key factors define the PNG landscape and all of these have direct relevance for the LBL program. First, English literacy is low in PNG and it is estimated that only between $20-25 \%$ of the population can communicate fluently in English, the language of government and education. In some communities, English is the fifth or sixth language behind local languages and dialects, presenting a challenge for LBL and its development officers who are encouraged to deliver programs in English. Second, while the PNG school curriculum makes allocations for physical education (PE) in elementary, primary and secondary schools, PE sessions are rarely implemented and depend entirely on teachers' willingness and ability to conduct classes. However, with rugby league being the country's favourite sport - and official timeslots allocated for PE in the curriculum - opportunities for the LBL team to better engage schools and teachers are available. Third, many students are disengaged from school for various reasons; in some communities, the presence of a teacher is irregular and in other cases, children are required to support families at home during school time. Finally, even if children attend school and classes are delivered, the learning environment is challenging. Large class sizes with 50 to 90 students are not uncommon and, unfortunately, school facilities and rooms often do not cater adequately for the number of students per class. The recent policy change towards free education for every child in $\mathrm{PNG}$ - intended to lead to positive education outcomes - has in fact led to a situation which can limit active participation and engaging class experiences for students.

\section{Research Context}

\section{The League Bilong Laif (LBL) Program}

It is important to highlight in more detail the aims, partnerships, stakeholders and broader operations of the LBL program to further contextualise the initiative. LBL is an SFD program 
that uses rugby league activities to support education outcomes for elementary and primary school children in PNG. It is funded by the Australian Government and delivered by the National Rugby League (Australia) (NRL) in partnership with the PNG National Department of Education and Bougainville's Department of Education. The LBL program is entirely led and managed by Papua New Guinean staff and volunteers in PNG. Originally, the local PNG Rugby Football League (PNGRFL) sought to be the in-country partner to deliver the LBL program; however, due to issues regarding mismanagement and substantial governance challenges, the project was handed directly to the NRL. While LBL's primary goals are educational, a long-term goal of the program is to work with PNGRFL to improve organisational and management capacity with the aim of partnering in the delivery of LBL in the future.

The LBL program is currently conducted in schools across four regions of PNG: the National Capital District (Port Moresby), the Eastern Highlands (Goroka), East New Britain (Kokopo) and the Autonomous Region of Bougainville (Buka). At the schools, each participating class receives six sessions of rugby league-related on-field and in-classroom activities delivered by development officers (DOs), staff and volunteers. Sessions are designed to be non-contact and non-competitive and provide accessible sporting and educational opportunities for children of all abilities. The program uses a range of rugby league-themed educational resources and reading materials that the NRL has developed with Macmillan Education Australia. These materials aim to encourage healthy lifestyles and boost students' physical, social, literacy and maths skills in an exciting and accessible way. For example, reading books comprise rugby-related stories and examples, and maths exercises focus on using rugby league data, such as match results, player and on-field statistics.

From a participation and capacity-building perspective, one of the key objectives of the program is to introduce a new generation of female participants to the sport with specific opportunities for women to forge a career in rugby league. The focus on gender equity and empowerment is important, as most SFD programs provided around the world are provided for and taken up by boys, while girls' access to sport and physical activity remains restricted (Schulenkorf, Sherry and Rowe, in press). This is no different in the context of PNG, where boys and girls hardly play together; girls are considered second grade when it comes to active participation in sport and physical activity; and women are rarely represented in the sport administration and management circles. Hence, the LBL development officers, half of whom 
are women, are trained to deliver key social messages on 'Respect' and equality in addition to highlighting the 'Importance of Education for all Papua New Guineans'. These core program values are communicated alongside school-specific messages, such as anti-bullying, that the program aims to address. In an attempt to grow and sustain the LBL program, LBL staff train local school teachers to run and facilitate the program. In particular, the DOs and program volunteers actively involve and mentor teachers through the six-session program. After the first term, schools are left with a resource pack so teachers can continue to deliver the program in terms two and three; ongoing support, resources, training and follow up visits are provided by the NRL DOs to secure continuous and sustainable program implementation.

\section{Research Approach}

Our qualitative investigation into the LBL pilot program (2013-2014) aimed to evaluate progress towards stated development outcomes; moreover, we focused on identifying indicators of program success held by the various stakeholders in both Australia and PNG. Following an interpretive mode of inquiry, data was collected in a two-week period in November 2014 through a combination of 23 in-depth interviews and focus groups. In total, 33 individual representatives from relevant organisations and government departments in the areas of sport, education and community development, took part in this research. The data collated largely represents 'local' voices and the perceptions of stakeholders who have been directly involved with LBL - in other words, specific focus has been placed on capturing local knowledge as a central element for culturally relevant and meaningful research (Jeanes, 2013; Manley et al., 2014; Schulenkorf, Sugden and Burdsey, 2014). In addition to the faceto-face methods described above, two experienced SFD researchers undertook an in-country visit to all program sites for observation and documentation purposes.

When all data was collected and interviews and focus groups were transcribed, we engaged in a thematic analysis process that was facilitated by the NVivo 10 qualitative analysis software package. The themes presented in the following section were identified through a systematic coding process recommended by Miles, Huberman and Saldana (2014), which includes a broad read through, a search for recurring concepts and patterns, and then a grouping together of concepts and patterns into themes that address - or are aligned with the research aims.

\section{Findings - Progress Achieved through the LBL Pilot}


The purpose of this research was to examine findings from the qualitative review of the pilot phase of the LBL project, and to provide implications for program design and delivery for education outcomes through a sport-for-development program. The challenges of working within schools, training teachers/LBL staff and the complex stakeholder relationships are addressed specifically in the following sections. Based on the analysis of all interviews and focus groups conducted in PNG in November 2014, we provide findings clustered loosely into the following themes: Community and stakeholder engagement; LBL staff training; and teacher training and engagement.

\section{Community and Stakeholder Engagement}

Local and international stakeholders are significant contributors to LBL's operations in schools around the country. Interviewees reported a number of achievements but also challenges for the program in terms of stakeholder engagement. On the positive side, there has been significant interest in - and support for - LBL by teachers, parents and the wider community. Principals actively requested the program be implemented in their school:

Schools are coming up, approaching us to run the program in their area... it's not us going to the schools, they're actually coming and asking us to go to their schools.

Similarly, community awareness and reception of LBL have been excellent. One stakeholder identified that this had a flow-on effect on community perceptions of rugby league in PNG as a valuable tool for positive community development:

As so many people have commented, even the parents have turned out to see what their students were doing... It's amazing to see this LBL really getting so much interest in the schools as well as the community ... the smaller ones are really into this. They are not just doing the stuff that they watch on TV, but, you know, they are learning with rugby league as the tool.

Moreover, good progress was made regarding the relationship building aspects of the program, which relate particularly to engagement with political figureheads, and to some extent, the PNGRFL. Both of these stakeholders are important contributors to communicating and leveraging LBL's key messages. In the light of the initial challenges to the LBLPNGRFL relationship, the following statement from one of the PNGRFL executives is an encouraging account of recent developments in the NRL-PNGRFL relationship: 
The good thing is we've got some understanding, now we're able to work with them, they're actually helping us with our governance things, we're running... concurrent programs and we've developed understanding to go forward and actually, we're looking at an MOU in the next one or two months on ... how we can assist each other with the programs. From a shaky beginning, I think we've established some understanding and the future, we can only get better.

An unsurprising level of dysfunction in the relationship between the two organisations was noted; however, as the quote above illustrates, the relationship and the partnership between the two parties is improving. This finding is particularly intriguing from an engagement and power relations perspective, given the wider context of a program that has been largely funded and controlled by an international sporting body, yet is delivered by a local team that works separate from the country's official national federation.

\section{LBL Staff Training}

When LBL started operations in 2013, there was a lack of appropriately skilled SFD staff available in-country, meaning there was a need to focus on staff training and development to enable program delivery. Training and development of LBL staff covered program-specific training, as well as broader skills, such as working with children, project management and logistics, and included a specific focus on the equitable recruitment and development of female DOs. During the pilot, the senior staff and full-time DOs received the most training, with the aim that each lead DO then passes on the training as required to their casual program delivery staff following a 'train the trainers' approach (see Sugden, 2006). This training occurred predominantly in PNG, with both regional specific training and annual programwide training provided for the entire staff cohort. In addition, most senior staff have been invited each year to Australia for professional development opportunities within the NRL on a regular basis. During 2015, three staff received Australian Aid Fellowships, which facilitated travel to Australia for a two-week intensive of peer learning and mentoring within the NRL organisation. Functional training provided by NRL staff was reported to have been useful in developing professional technical skills for program delivery, as well as soft-skills that impacted positively on a personal level (confidence, self-esteem etc.). For example:

I've learnt a lot of things. I got involved in this program and learnt how to organise big events and how to talk... and how to liaise with important people and also organise important activities. Also, I see that little kids look up to us as role models. 
So how we carry ourselves around is really important. Yeah, as a role model for younger girls who want to be rugby players just like us.

As role models for younger children, respectful behaviour and etiquette were considered important elements for success; the desire to progress and the drive to achieve the best possible development outcomes were cited as crucial traits in a role model.

I'm now accepted to do... a Bachelor of Management degree. [I] just paid the school fee and I'm happy because I'm attached to the program and this program has allowed me to recognise this opportunity - and it will push me through. To have [LBL] stated on my CV surely helped my application... I believe this is why they accepted me.

This statement suggests that for staff members, involvement in the LBL program had positive impacts on their professional development. Here, the NRL's focus on employing only PNG locals as staff members for the LBL program clearly served its purpose. It allowed for the upskilling of talented staff, yet at the same time it provided and developed culturally informed and sensitive local leaders. It is one aspect that sets the program apart from many of the other development initiatives implemented across the Pacific Islands.

One of the things that really struck me and I was really impressed with... is how $[L B L]$ was run and managed and the level of expertise that ... that the program deliverers had. I don't see that often unless it's foreign people coming into country... But [LBL] was delivered by Papua New Guineans!

\section{Teacher Training and Engagement}

Training and development of teachers is critical, given their role in the sustained engagement of schools with LBL. During the pilot phase, LBL staff conducted teacher information sessions at participating schools; teacher training focused on the conceptual model of LBL and practical implementation of skills related to the program. One key highlight of the teacher training initiative was the large number of participating teachers $(n=638)$, particularly female teachers $(62 \%)$. Overall, the training provided by LBL staff was prescriptive in nature; subsequently, the pedagogical approach advocated by the program concentrated on imparting knowledge from LBL staff to teachers in a directive way. Therefore, the teachers had limited input into the content and delivery of the program. What emerged strongly from interviews with teaching staff were their concerns about the subsequent implementation of the LBL program after the introductory training was completed. After the initial teacher 
training sessions, most teachers commented that they were not ready to run rugby programs with their students without continued support from DOs. For example, one teacher argued:

Two of us were selected to attend a course at the university for two days. We really enjoyed ourselves out there! But being a teacher and trying to learn to be a coach was something a little bit different than just being a classroom teacher... We went through some training sessions and then we were asked to implement that at our schools.

Similarly, the rugby-specific educational development sessions in the classroom needed further adjustment. DOs reported that much of the content in the books/readers was Australian-centric and that a large amount of time was spent explaining English words and concepts rather than focusing on the acquisition of reading skills. Overall, it became obvious that although the teacher training provided some professional development for the teaching staff, the teachers were then left to their own initiative to negotiate delivery of the program within their school both on and off the pitch. Teachers expressed a need to receive regular follow-up training in both rugby league and LBL methodology, as one teacher explained:

What they want children learn is also what the teachers need to know... When the children are throwing the ball in the air saying, "this is this kind of pass", we must know if that is correct and what is going on. Otherwise the children will be teaching us, so we should be knowledgeable and then we can pass the knowledge on to the children.

School teachers' expectations of DOs, in terms of delivery and facilitation of LBL, were high. Feedback from DOs revealed teachers' varying levels of willingness and ability to implement activities or assist DOs in sessions; in fact, despite their having completed the LBL training they often expected the NRL team to continue to drive and lead activities. Teachers reported that inadequate staffing at their schools impacted program delivery and as a consequence, they found it challenging to manage large class groups and to achieve the goal of 'everyone participates' - an overarching philosophy of the LBL program. Similar concerns were raised by the DOs; however, they were more comfortable dealing with larger groups on the sporting fields as this formed part of their educational background and sporting expertise in PNG.

Overall, despite the challenges, teachers reacted positively to the LBL training program and its intention; however, sustaining teacher engagement was a key issue that 
emerged from participant interviews. Exploring the interactional encounters between teachers and DOs and the nature of training delivery will be important aspects to understand the micro-level factors that could potentially impact on the LBL program. These issues are significant because of the central role ascribed to teachers in the transmission of LBL's social and educational aims in the long run. Hence, deeper investigations into these relationships will have to form part of the next phase of the LBL research program. Findings should provide better knowledge and recommendations around partnership management and close educational engagement that provides adequate support for effective program delivery.

\section{Discussion}

Building on our thematic findings, we now discuss critical opportunities and challenges of the LBL program which may have implications for any future education-focused SFD initiatives in the Pacific and beyond.

\section{Community and Stakeholder Engagement}

The LBL program operates in an interesting organisational environment: overseen and financially supported by the Australian Rugby League Commission (via the NRL), but implemented by local staff in PNG. The other key partners are also a combination of international and local constituency: the Australian Government, represented through the Ministry of Foreign Affairs and Trade, and the PNG Government and its Department of Education. Therefore, close cooperation with the curriculum development unit of the PNG Department of Education is required in order to establish, consolidate and extend LBL within the educational system. Of significant concern for LBL organisers, was the education system and educational infrastructure in PNG. In short, schools are under-resourced and overenrolled and teaching staff are poorly paid and often unreliable.

The ongoing delivery and sustainability of LBL requires investment in and engagement with teaching staff on a regular basis, to avoid the ad hoc and inconsistent delivery in which "critical pieces of the puzzle are ignored" (Njelesani, 2011: 435). However, relationship building across countries, government departments, sport bodies and communities presents a complex context for any SFD trying to build capacities and make a positive socio-educational impact in disadvantaged communities (Coalter, 2015). In this particular case, despite official partnerships with relevant institutions, LBL's relationship with the PNG Department of Education has been limited and deserves to be intensified beyond the LBL pilot phase. Here, it important that realistic expectations are set and 
communicated, especially given the socio-economic, cultural and geographical context of PNG. LBL is operating within the practical realities of an aid-dependent, instable sociopolitical and cultural environment which can impact on - or undermine - rigorous and 'ideal' design processes. Further, while the local-international mix has proved effective in some respects (e.g. regarding the overall awareness and support of the program in PNG communities), it has also thrown up some challenges, particularly regarding the relationship between LBL and PNGRFL. To establish long-term sustainability - particularly for demonstrable education outcomes - additional capacity and greater integration must be built into the local federation and systems (Jeanes, 2013; Njelesani, 2011; Spaaij \& Jeanes, 2013). For this to be achieved, it will take extra time, resources and a strong commitment towards cooperation and engagement so that trust can be established between project partners. Finally, it remains to be seen how the international-local relationship between the official rugby bodies develops given the uneven power relations between the NRL and the PNGRFL (Darnell, 2010; Hayhurst, 2009). To establish a level playing field, the next phase of the LBL program therefore deserves a strong focus on creating a shared understanding of roles and responsibilities for all stakeholders involved.

Increased interest in LBL by schools, and requests to have program visits, represented an important development for LBL as it demonstrated general support for, and acceptance of, LBL - a critical first step towards strong local engagement and potential long-term support, involvement and ownership (Schulenkorf, 2012). Beyond the school grounds, positive wordof-mouth resulted in strong community interest for the program and high attendance rates at LBL end-of-term festivals and school gala-days. Once more, a favourable community perception is a positive indicator for program impact and an important first step in the process of sustaining programs in a community (Burnett, 2014). However, previous studies have shown that despite early enthusiasm and support, only those programs that maintain a close relationship with key stakeholders - particularly local supporters - can achieve long-term sustainability (Schulenkorf et al., 2014).

Another important aspect is the provision of conceptual clarity around the role of deliverers and supporters in the development process, something that has also been shown to be influential on education outcomes (Armour \& Duncombe, 2012). Because of its structure, the LBL program unavoidably entered into a web of complex socio-cultural and educational relationships and although the program aims to encourage local ownership, the LBL initiative to date remains externally controlled by the NRL. The challenges associated with this are 
exemplified through various interactional relations, including difficulties around teacher engagement and the questioning of particular pedagogical approaches, as well as the challenging relationship between LBL and PNGRFL. Spaaij and Jeanes (2013) have previously argued that externally imposed pedagogies may negatively impact program outcomes as they undervalue existing knowledge. Therefore, improving stakeholder engagement with key players in the system and hence making the program content more contextually informed and relevant is likely to assist in alleviating such issues.

\section{LBL Staff Training}

The design phase of the LBL program identified a lack of appropriately skilled SFD staff available in country. Hence, there was a need from the outset for the LBL organisers to prioritise staff training and development to build local capacity and encourage local ownership of LBL - something that has consistently been identified as key to achieving intended development outcomes and long-term sustainability (Coalter, 2008; Schulenkorf, 2012; Schulenkorf et al, 2014). Unfortunately, LBL's implementation was not afforded the luxury of time to train and develop staff prior to commencement, as is generally recommended (for example, Coalter, 2008). Rather, training and development of LBL staff occurred almost simultaneously with the delivery of the program. Upon reflection, this adhoc approach to training restricted strategic planning exercises which could have potentially led to a more efficient delivery of projects, including a better service for program staff and volunteers under a well-designed 'train the trainers' approach (see Sugden, 2006). Instead, LBL had to retrospectively support local staff and provide (international) development opportunities that were largely available because of the strong position and support of the NRL in Australia.

An identified strength of the program was its delivery by local staff. Here, the LBL program has demonstrated capacity building opportunities for the PNG staff. The different

roles in the management, delivery and evaluation of the project not only embed the program into the local (sport) communities (Coalter, 2008), but they also present a secondary consequence of people's involvement: personal empowerment. Staff see LBL as an opportunity for their own personal and professional development and as discussed, they are expected to subsequently pass on these new skills and knowledge to their casual staff, teachers and volunteers within the community. Beyond the standard 'train the trainers' experiences, the three recipients of the Australian Aid Fellowships spoke highly of their 
international educational opportunity that further developed their professional practice. At present, there is however only anecdotal evidence that suggests that knowledge transfer towards support staff and volunteers has already occurred. Further analysis to unpack the assumed link between personal and community empowerment - often assumed but not realised in SFD projects (Schulenkorf et al, 2014) - is therefore required as the program develops. Nonetheless, as expressed by Coalter (2008): "the production of peer leaders/coaches/educators [in itself] is a major outcome and fundamental to the quality and sustainability of the programme [sic]" (p.17).

\section{Teacher engagement and training}

Among the most significant stakeholders in the LBL program development process are the local school teachers. Their involvement is particularly pertinent for program sustainability and program organisers had identified an 'increased capacity of teachers' as a key outcome of the pilot phase. In particular, the LBL team had the clear objective of introducing and training teachers in the LBL philosophy with the intended outcome of active teacher engagement during LBL sessions during the first school term of the year. While LBL DOs reported good uptake of the training sessions and some success in co-delivery, there were also reports of a lack of teacher engagement and limited sport skills and expertise in PE sessions, which negatively impacted session delivery. Teachers commented that they lacked confidence in their own knowledge about rugby league skills and wider LBL aims. Some teachers simply suggested LBL staff were the 'sport experts' and should run the sessions independently. This suggests that, despite ostensible support, teachers felt overwhelmed or ill-prepared for independent program delivery.

At the same time, differing perceptions of ownership of, and responsibility for, the program, may have resulted in the described lack of willingness and ability to participate. Cultural misunderstandings regarding program responsibility and international support have previously been identified as challenges in SFD that can result in tensions between local and international stakeholders (see Schulenkorf, 2010b). In fact, perceived power imbalances may have played a role here, as teachers decided to - and at times preferred to - rely on experts to deliver programs (Darnell, 2010). Perhaps there was a well-intended assumption by LBL organisers that one or two training sessions were sufficient in getting teachers on board and providing them with enough knowledge and skill to run SFD activities independently. Clearly, the upskilling of non-sport teachers deserves more time and ongoing support, as 
highlighted in the interviews and in previous SFD research around local skill development and empowerment (Sugden, 2006; Schulenkorf, 2012). These aspects will require the LBL organisers to adjust their approach to teacher training and they should provide important lessons learnt for similar education-based SFD programs in the future.

Finally, it is important to note that micro-relations around SFD programs do not occur in a 'social vacuum' (Jeanes, 2013). Understanding the local context and teachers' perceptions is imperative for developing SFD programs and critically analysing the progress of such initiatives. In PNG, there are certainly wider contextual factors shaping teachers' engagement and long-term delivery of the LBL program. For example, there are difficulties with the status and reliability of teachers because of low pay rates; in addition, they face significant educational challenges due to large class sizes, children's irregular attendance and wider cultural attitudes towards schooling. Consequently, in order to ensure that the LBL program is sustained, it is vital to provide teachers with consistent support and adequate training to avoid compounding wider structural issues. Previous literature has highlighted the importance of listening to local voices and jointly developing a sense of ownership over projects to assist practitioner empowerment and engagement (e.g. Coakley 2011; Jeanes 2013; Schulenkorf et al., 2014). Here, the LBL program may have to adopt a pedagogical approach that creates a sense of knowledge co-construction, rather than being directive in nature, which could allow the teachers to identify more strongly with their important role in the program. Additionally, as an important structural change on a macro-level, broader teacher education in sport, PE and the LBL philosophy needs to occur in a strategic and organised manner (see e.g. Stidder \& Haasner, 2007; Sugden, 2006). A first significant step will see closer cooperation with the Department of Education and the inclusion of the LBL program as part of the broader PNG sport and PE curriculum - a key objective for the next phase of the program.

\section{Conclusion}

This paper has provided insights into an education-based SFD program designed and delivered with the ambitious aim of improving education outcomes for the PNG community. Our study has highlighted that for any meaningful discussion around the program, its evaluation and potential educational impacts, the importance of considering the local context - in this case the PNG education system and variety of local cultures, norms and values cannot be underestimated. 
In analysing and discussing the LBL's pilot phase in critical detail, the most conclusive areas of progress were those reflecting Coalter's (2008) idea of outputs. While the lack of staff 'know-how' was a problematic issue at the beginning of the program, it appears the NRL/LBL investment in human resources is paying off; LBL staff reported personal and professional development outcomes. Moreover, their engagement with - and ownership of LBL saw them confident in delivering education-based SFD sessions at local schools, and offering ideas for development and improvement of the program. On the other hand, stakeholder management and teacher engagement were identified as significant challenges for the LBL organisers. For the next phase of this program, efforts need to be directed into developing strengthened relationships within the national educational department and identifying barriers to teacher engagement. As discussed, this process deserves a bottom-up approach to program development that builds on the perspectives of those directly involved. On the macro-level, further consolidation and development of strong stakeholder relationships will also assist in the ambitious attempts to embed LBL more deeply within the PNG education system. For instance, working directly with the PNG curriculum development unit, school principals and teachers will help identify areas for improvements in educational resources, and finding opportunities for LBL to assist in curriculum change.

At this early stage of the LBL pilot, it is impossible to assess education impacts on children; however, it appears that the parameters are in place to allow for future benefits to occur. Regardless of the potential of such a program, a number of questions remain: how can we measure the cause-effect link between the LBL education sessions and desired education development outcomes? The causal link between SFD programs and outcomes has been consistently identified as a challenge, with criticism facing those organisations who overstate the impact of their programs on the community (Coalter, 2013; 2015). Objective measuring seems impossible, so should the focus instead be on identifying individual and social outcomes that are facilitated in an education setting? At present, there is some limited qualitative feedback from the staff and students on enjoyment of classroom rugby league sessions, the use of the literacy resources and opportunities for reading and writing in a fun and engaging context. Arguably, this presents a first important step towards learning and development: the LBL program provides another opportunity to draw the students into the classroom. Whatever the focus of future SFD-based education initiatives and evaluations will be, it seems important to discuss, design and deliver ideas in a culturally relevant and meaningful way. Only if all stakeholders are convinced by, committed to, and comfortable 
with the overall purpose of the initiative, is there an opportunity to sustain and potentially grow impacts for wider community benefit.

\section{References}

Armour, K., \& Duncombe, R. (2012). Changing lives? Critical evaluation of a school-based athlete role model intervention. Sport, Education and Society, 17(3), 381-403.

Bailey, R. (2005). Evaluating the relationship between physical education, sport and social inclusion. Educational Review, 57(1), 71-90.

Beutler, I. (2008). Sport serving development and peace: Achieving the goals of the United Nations through sport. Sport in Society, 11(4), 359-369.

Black, D. R. (2010). The ambiguities of development: implications for 'development through sport'. Sport in Society, 13(1), 121-129.

Bodey, K. J., Schaumleffel, N. A., Zakrajsek, R., \& Joseph, S. (2009). A strategy for coaches to develop life skills in youth sport. Journal of Youth Sports, 4(2), 16-20.

Burnett, C. (2006). Social impact assessment and sport development: Social spin-offs of the Australia-South Africa junior sports programme. International Review for the Sociology of Sport, 36(1), 41-57.

Burnett, C. (2014). The impact of a sport-for-education programme in the South African context of poverty. Sport in Society, 17(6), 722-735.

Casey, M. M., Payne, W. R., \& Eime, R. M. (2009). Partnership and capacity-building strategies in community sports and recreation programs. Managing Leisure, 14(3), 167176.

Coakley, J. (2011). Youth sports: What counts as "positive development"? Journal of Sport and Social Issues, 35(3), 306-324.

Coalter, F. (2008). Sport-in-development: A monitoring and evaluation manual. London: UK Sport, accessed 10 Jan 2014 from:

http://assets.sportanddev.org/downloads/10_sport_in_development_a_monitoring_and _evaluation_manual.pdf 
Coalter, F. (2010). The politics of sport-for-development: Limited focus programmes and broad gauge problems? International Review for the Sociology of Sport, 45(3), 295-314.

Coalter, F. (2015). Sport-for-change: Some thoughts from a sceptic. Social Inclusion, 3(3), 19-23. doi: 10.17645/si.v3i3.222.

Darnell, S. C. (2010). Power, politics and "sport for development and peace": Investigating the utility of sport for international development. Sociology of Sport Journal, 27(1), 5475.

Darnell, S. C., \& Hayhurst, L. (2011). Sport for decolonization: Exploring a new praxis for sport for development. Progress in Development Studies, 11(3), 183-196.

Darnell, S. C., \& Hayhurst, L. (2012). Hegemony, postcolonialism, and sport-fordevelopment: A response to Lindsey and Grattan. International Journal of Sport Policy \& Politics. 4(1), 111-124.

Edwards, M. B. (2015). The role of sport in community capacity building: An examination of sport for development research and practice. Sport Management Review, 18(1), 6-19. doi: 10.1016/j.smr.2013.08.008.

Eime, R. M., Young, J. A., Harvey, J. T., Charity, M. J. \& Payne, W. R. (2013). A systematic review of the psychological and social benefits of participation in sport for children and adolescents: Informing development of a conceptual model of health through sport. International Journal of Behavioral Nutrition and Physical Activity, 10(1), 98-119.

Ekholm, D. (2013). Sport and crime prevention: Individuality and transferability in research. Journal of Sport for Development, 1(2), 26-38.

Hastie, P. A., \& Buchanan, A. M. (2000). Teaching responsibility through sport education: Prospects of a coalition. Research Quarterly for Exercise \& Sport, 71(1), 25-35.

Hawe, P., Noort, M., King, L., \& Jordens, C. (1997). Multiplying health gains: The critical role of capacity-building within health promotion programs. Health Policy, 39(1), 29-42.

Hayhurst, L. M. (2009). The power to shape policy: Charting sport for development policy discourses. International Journal of Sport Policy, 1, 203-227. 
Jeanes, R. (2013). Educating through sport? Examining HIV/AIDS education and sport-fordevelopment through the perspectives of Zambian young people. Sport, Education and Society, 18(3), 388-406.

Khoo, C., Schulenkorf, N. \& Adair, D. (2014). The opportunities and challenges of using cricket as a sport-for-development tool in Samoa. Cosmopolitan Civil Societies Journal, 6(1), 76-102.

Manley, A., Morgan, H., \& Atkinson, J. (2014). Mzungu!: Implications of identity, role formation and programme delivery in the sport for development movement. International Journal of Sport Policy and Politics, doi: 10.1080/19406940.2014.962072

Miles, M. B., Huberman, A. M., \& Saldana, J. (2014). Qualitative Data Analysis: A Methods Sourcebook (3rd edn.). Thousand Oaks: Sage.

Njelesani, D. (2011). Preventive HIV/AIDS education through physical education:

Reflections from Zambia. Third World Quarterly, 32(3), 435-452.

OASC (2015). Papua New Guinea 2015 Crime and Safety Report. Accessed 25/06/15 from https://www.osac.gov/pages/ContentReportDetails.aspx?cid=17301.

Richards, J., Kaufman, Z., Schulenkorf, N., Wolff, E., Gannett, K., Siefken, K., \& Rodriguez, G. (2013). Advancing the evidence base of sport for development: A new open-access, peer-reviewed journal. Journal of Sport for Development, 1(1).

Schulenkorf, N. (2010a). Sport events and ethnic reconciliation: Attempting to create social change between Sinhalese, Tamil and Muslim sportspeople in war-torn Sri Lanka. International Review for the Sociology of Sport, 45(3), 273-294. doi: $10.1177 / 1012690210366789$

Schulenkorf, N. (2010b). The roles and responsibilities of a change agent in sport event development projects. Sport Management Review, 13(2), 118-128. doi: 10.1016/j.smr.2009.05.001

Schulenkorf, N. (2012). Sustainable community development through sport and events: A conceptual framework for sport-for-development projects. Sport Management Review, 15(1), 1-12. 
Schulenkorf, N., \& Sugden, J. (2011). Sport for development and peace in divided societies: Cooperating for inter-community empowerment in Israel. European Journal for Sport and Society, 8(4), 235-256.

Schulenkorf, N., Sugden, J., \& Burdsey, D. (2014). Sport for development and peace as contested terrain: Place, community, ownership. International Journal of Sport Policy, 6(3), 371-378. doi: 10.1080/19406940.2013.825875

Schulenkorf, N., Sherry, E., \& Rowe, K. (in press). Sport-for-Development: An integrated literature review. Journal of Sport Management. doi: http://dx.doi.org/10.1123/jsm.20140263

Sherry, E. (2010). (Re)engaging marginalized groups through sport: The Homeless World Cup. International Review for the Sociology of Sport, 45(1), 59-71.

Stidder, G., \& Haasner, A. (2007). Developing outdoor and adventurous activities for coexistence and reconciliation in Israel: An Anglo-German approach. Journal of Adventure Education and Outdoor Learning, 7(2), 131-140. doi: 10.1080/14729670701731052

Sugden, J. (2006). Teaching and playing sport for conflict resolution and co-existence in Israel. International Review for the Sociology of Sport, 41(2), 221-240.

Spaaij, R. (2009). The social impact of sport: Diversities, complexities and contexts. Sport in Society, 12(9), 1109-1117.

Spaaij, R., \& Jeanes, R. (2013). Education for social change? A Freirean critique of sport for development and peace. Physical Education and Sport Pedagogy, 18(4), 442-457. doi: 10.1080/17408989.2012.690378

Svensson, P. G., \& Hambrick, M. E. (in press). "Pick and choose our battles" Understanding organizational capacity in a sport for development and peace organization. Sport Management Review. doi: 10.1016/j.smr.2015.02.003

Zeigler, E. F. (2003). Guiding professional students to literacy in physical activity education. Quest (00336297), 55(4), 285-305. 